\title{
Uni-directional GaN-on-Si MOSHEMTs with High Reverse-Blocking Voltage based on Nanostructured Schottky Drain
}

\author{
Jun Ma and Elison Matioli \\ École polytechnique fédérale de Lausanne (EPFL), \\ Lausanne, CH-1015, Switzerland. \\ E-mail: jun.ma@epfl.ch, elison.matioli@epfl.ch
}

\begin{abstract}
In this work we present uni-directional GaN-on-Si MOSHEMTs with state-of-the-art reverse-blocking performance. We integrated tri-anode Schottky barrier diodes (SBDs) with slanted tri-gate field plates (FPs) as the drain electrode, and achieved a high reverse-blocking voltage $\left(V_{\mathrm{RB}}\right)$ of $-759 \pm 37 \mathrm{~V}$ at $0.1 \mu \mathrm{A} / \mathrm{mm}$ with grounded substrate. The hybrid Schottky drain did not degrade the $\mathrm{ON}$-state performance when compared with conventional ohmic drain, and the turn-ON voltage $\left(V_{O N}\right)$ was as small as $0.64 \pm 0.02 \mathrm{~V}$. These results show the potential of GaNon-Si transistors as high-performance uni-directional power switches, and open enormous opportunities for future highly integrated $\mathrm{GaN}$ power devices.
\end{abstract}

Keywords-GaN; HEMTs; SBDs; reverse blocking; slanted trigate; tri-anode.

\section{INTRODUCTION}

Lateral GaN-on-Si HEMTs are very promising for power applications, yet their bi-directional conduction is not ideal in many topologies of power converters. To achieve high-voltage reverse-blocking (RB) capability, a power diode is added in series with the HEMT, which complicates the circuit design, increases the ON-resistance $\left(R_{\mathrm{ON}}\right)$ and parasitic elements, and degrades the efficiency of power conversion. HEMTs with integrated RB capability (RB-HEMTs) would therefore be highly desirable to address these issues, however, in the few reports on RB-HEMTs in the literature [1]-[6], the devices exhibited a relatively large $V_{\mathrm{ON}}$, a significant increase in forward voltage $\left(\Delta V_{\mathrm{F}}\right)$, a small $V_{\mathrm{RB}}$ as well as a large reverse leakage current $\left(I_{R}\right)$, limited by the SBDs integrated in their drain electrodes.

Recently we have proposed to reduce the $V_{\mathrm{ON}}$ and $I_{\mathrm{R}}$ in GaN SBDs using a tri-anode structure [8], [9], and presented its capabilities for GaN RB transistors [10]. In addition, we demonstrated a slanted tri-gate structure to improve the breakdown voltage of lateral GaN devices [11], [12]. These results paved the path for high-performance GaN RB-HEMTs from both theoretical and experiment aspects. In this work we extend these concepts to demonstrate high-performance GaN MOSHEMTs on $\mathrm{Si}$ with state-of-the-art reverse-blocking

This work was supported in part by the European Research Council under the European Union's H2020 program/ERC Grant Agreement 679425 and in part by the Swiss National Science Foundation under Assistant Professor (AP) Energy Grant PYAPP2_166901.

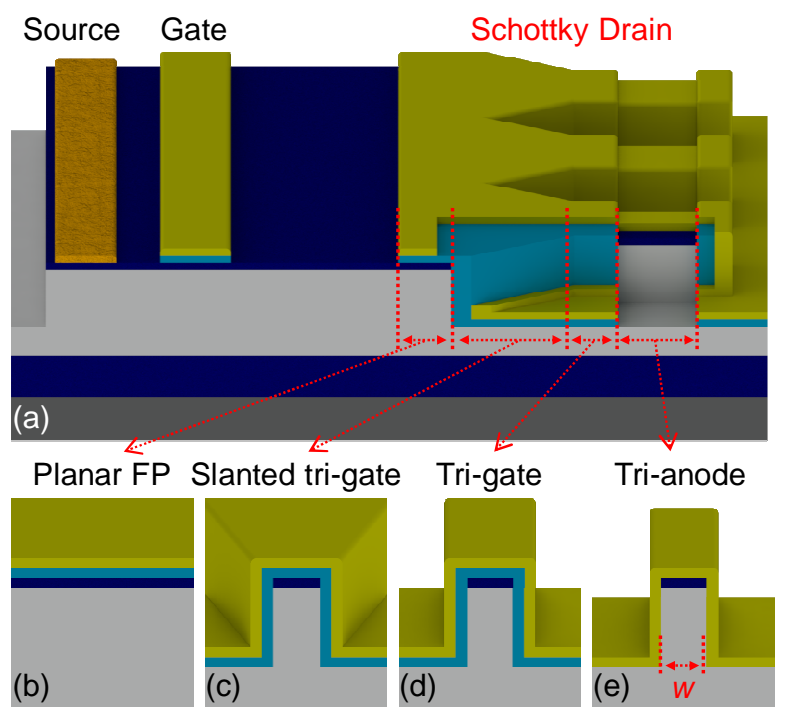
Oxide AIGaN

$\mathrm{GaN}$ Si

Fig. 1. (a) Schematic of the MOSHEMTs with the slanted tri-gate Schottky drain. Cross-sectional schematics of the (b) planar FP, (c) slanted tri-gate (sTG), (d) tri-gate (TG) and (e) tri-anode (TA) regions.

performance, using a novel tri-anode Schottky drain integrated with slanted tri-gate FPs. The devices presented a high $V_{\mathrm{RB}}$ of $759 \pm 37 \mathrm{~V}$ at $0.1 \mu \mathrm{A} / \mathrm{mm}$ and a small $I_{\mathrm{R}}$ of $65 \pm 11 \mathrm{nA} / \mathrm{mm}$ at $700 \mathrm{~V}$, measured with grounded substrate. The $V_{\mathrm{ON}}$ was $0.64 \pm$ $0.02 \mathrm{~V}$ and the $\Delta V_{\mathrm{F}}$ was as small as $0.7 \mathrm{~V}$, with little degradation in $R_{\mathrm{ON}}$ compared to devices with conventional ohmic contacts.

\section{DEVICE FABRICATION}

The devices with the tri-anode Schottky drain (tri-SCH) were fabricated on an $\mathrm{AlGaN} / \mathrm{GaN}$-on-silicon wafer, and their schematics are shown in Fig. 1(a)-(e). The fabrication process started with e-beam lithography to define the nanowires, which were then etched by inductively coupled plasma with a depth of $\sim 180 \mathrm{~nm}$. The width $(w)$ and spacing $(s)$ for the nanowires in the tri-gate and tri-anode region were both $300 \mathrm{~nm}$, while the $w$ in the slanted tri-gate region increased continuously from 300

(C) 2018 IEEE. Personal use of this material is permitted. Permission from IEEE must be obtained for all other uses, in any current or future media, including reprinting/republishing this material for advertising or promotional purposes, creating new collective works, for resale or redistribution to servers or lists, or reuse of any copyrighted component of this work in other works. 

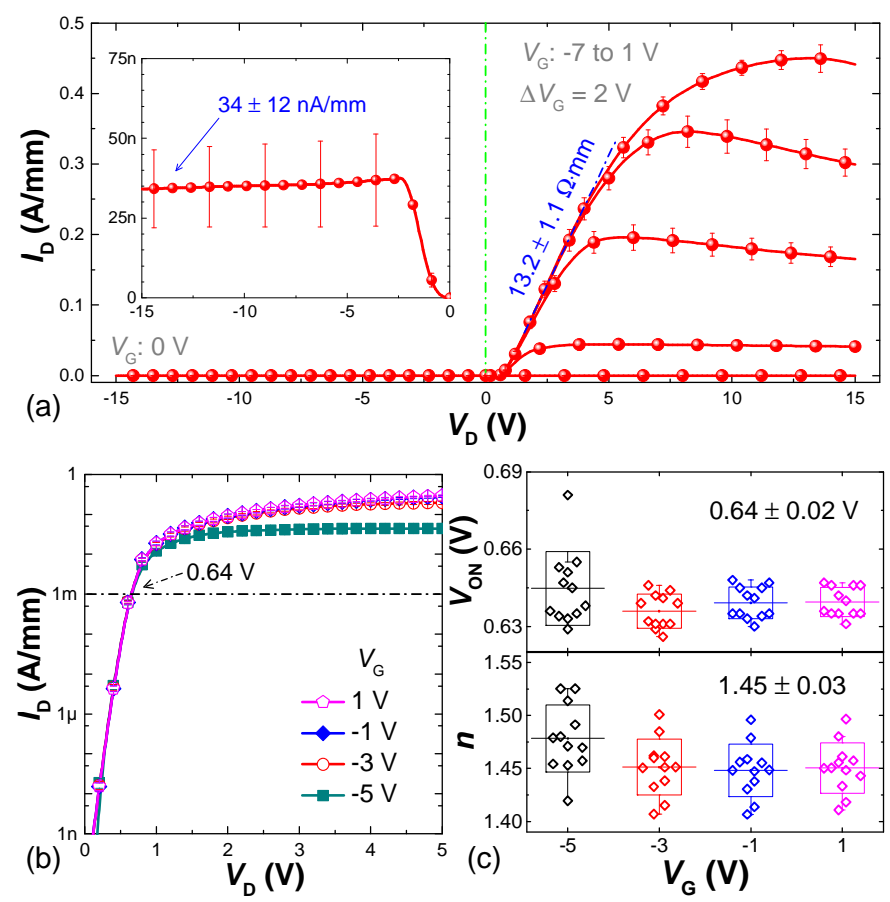

Fig. 2. (a) Output characteristics of devices with the slanted tri-gate $\mathrm{SCH}$ drain (tri-SCH), in which the inset shows the $I_{\mathrm{R}}$ in the tri-SCH at $V_{\mathrm{G}}=0 \mathrm{~V}$, and (b) their turn-on characteristics. (c) Dependence of the $V_{\mathrm{ON}}$ and the ideality factor (n) on $V_{\mathrm{G}}$

$\mathrm{nm}$ to $600 \mathrm{~nm}$ towards the gate. The devices were isolated from each other by mesa etching with a depth of $\sim 350 \mathrm{~nm}$, followed by deposition and annealing of ohmic metals as source electrodes. A stack of $10 \mathrm{~nm} \mathrm{SiO}_{2}$ and $10 \mathrm{~nm} \mathrm{Al}_{2} \mathrm{O}_{3}$ was deposited by atomic layer deposition as the gate dielectric, and then selectively removed in the tri-anode region. Finally the trianode and the gate were formed using $\mathrm{Ni} / \mathrm{Au}$, which was later used as the mask to remove the oxide in access/ohmic regions. The gate-to-source length $\left(L_{\mathrm{GS}}\right)$, gate length $\left(L_{\mathrm{G}}\right)$ and gate-todrain length $\left(L_{\mathrm{GD}}\right)$ were $1.5 \mu \mathrm{m}, 2.5 \mu \mathrm{m}$ and $12.5 \mu \mathrm{m}$, respectively. The lengths for the planar FP $\left(L_{\mathrm{FP}}\right)$, slanted trigate $\left(L_{\mathrm{STG}}\right)$, and tri-gate $\left(L_{\mathrm{TG}}\right)$ regions were $1.3 \mu \mathrm{m}, 0.7 \mu \mathrm{m}$ and $0.5 \mu \mathrm{m}$, respectively.

The working principle of the tri-SCH can be simply summarized as follows. The hybrid tri-anode SBDs pins the voltage drop at the Schottky junction and hence fixes the $I_{\mathrm{R}}$ at a small level [8],[9], despite the large reverse bias. On the other hand, the slanted tri-gate effectively spreads the electric field [11] and, together with the planar FP region [13], improves the $V_{\mathrm{RB}}$, which is similar to conventional slant FPs but in a more controllable manner. More detailed analysis of this structure can be found in Ref. [12].

MOSHEMTs with the same dimensions but conventional ohmic (OHM) and planar Schottky drain (p-SCH) electrodes were also fabricated on the same chip as references. All devices shared the same dimensions as the tri-SCH except for the different drain electrodes. The ohmic drain was formed by alloying $\mathrm{Ti} / \mathrm{Al} / \mathrm{Ti} / \mathrm{Ni} / \mathrm{Au}$, which was the same as the source electrode. The planar Schottky drain was the same as the trianode Schottky drain, however without the patterned features. All current values in this work, such as $I_{\mathrm{R}}$ and drain current $\left(I_{\mathrm{D}}\right)$, were normalized by the width of the device footprint,
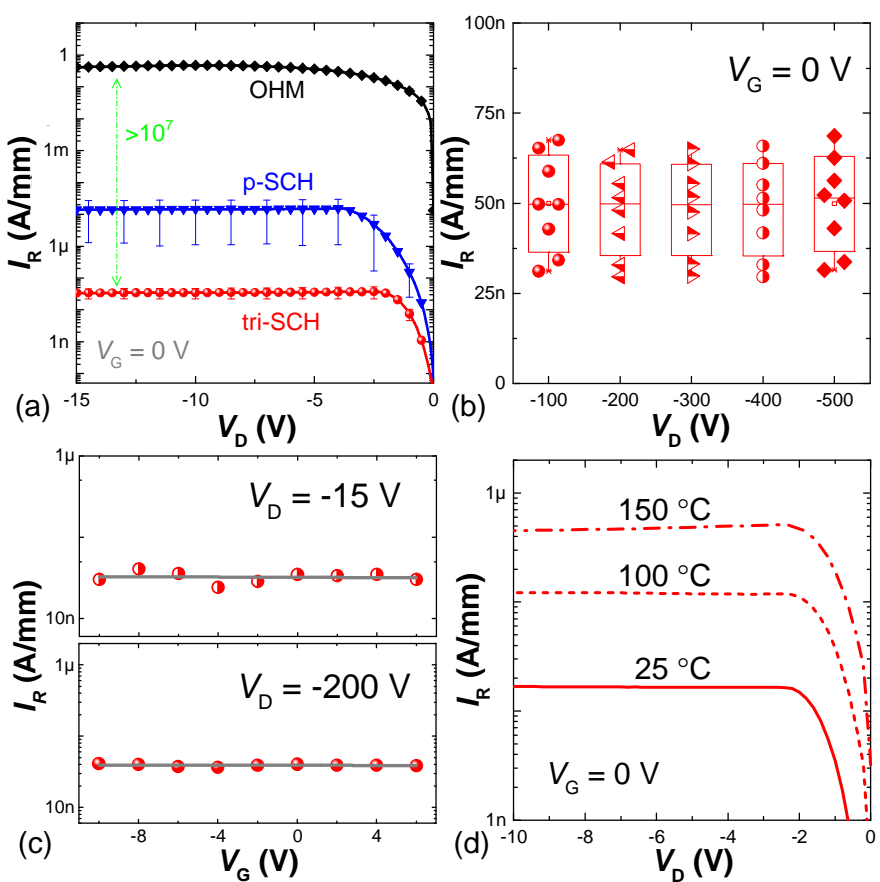

Fig. 3. (a) Comparison of $I_{\mathrm{R}}$ in devices with ohmic (OHM), planar Schottky (p$\mathrm{SCH})$ and tri-anode Schottky (tri-SCH) drains. Dependence of the $I_{\mathrm{R}}$ on $V_{\mathrm{D}}(\mathrm{b})$ and $V_{\mathrm{G}}(\mathrm{c})$ in the tri-SCH. (d) Dependence of the $I_{\mathrm{R}}$ in tri-SCH on temperature.

which was $60 \mu \mathrm{m}$. Twelve devices of each type were randomly chosen for the investigation, which defined the error bars presented in the results.

\section{RESULTS AND DISCUSSION}

Figure 2(a) shows the output characteristics of the tri-SCH, presenting its excellent performance as a uni-directional switch. Under forward $V_{\mathrm{D}}$, the differential $R_{\mathrm{ON}}$ and the maximum $I_{\mathrm{D}}$ were $13.2 \pm 1.1 \Omega \cdot \mathrm{mm}$ and $450 \pm 17 \mathrm{~mA} / \mathrm{mm}$, respectively. Under reverse biases, the $I_{\mathrm{R}}$ was $34 \pm 12 \mathrm{nA} / \mathrm{mm}$ at $V_{\mathrm{D}}=-15 \mathrm{~V}$ and $V_{\mathrm{G}}=0 \mathrm{~V}$. The $V_{\mathrm{ON}}$ was as small as $0.64 \pm$ $0.02 \mathrm{~V}$ (Fig. 2(b)) at $I_{\mathrm{D}}=1 \mathrm{~mA} / \mathrm{mm}$, due to the direct contact of the metal to the 2DEG at the sidewalls of the nanowire [14],[15]. The ideality factor $(n)$ was $1.45 \pm 0.03$, indicating the high quality of the Schottky contact despite the etching. Figure 2(c) plots the $V_{\mathrm{ON}}$ and $n$ at different $V_{\mathrm{G}}$, revealing very little dependence on $V_{\mathrm{G}}$.

The $I_{\mathrm{R}}$ in OHM, p-SCH and tri-SCH are compared in Fig. 3(a), all measured at $V_{\mathrm{G}}=0 \mathrm{~V}$. While the bi-directional nature of the OHM resulted in large reverse currents, reverseblocking capability was achieved in $\mathrm{p}-\mathrm{SCH}$ by replacing the ohmic drain with a planar Schottky drain. However, a large $I_{\mathrm{R}}$ was observed, similarly to other reports in the literature, leading to a small $V_{\mathrm{RB}}$ (defined at $0.1 \mu \mathrm{A} / \mathrm{mm}$ ) of $-0.9 \mathrm{~V}$. This reveals the unsuitability of the planar Schottky drain for practical and efficient power applications. The $I_{\mathrm{R}}$ was dramatically reduced by over two orders of magnitude in tri$\mathrm{SCH}$. This is because the voltage drop at the Schottky junction $\left(V_{\mathrm{SCH}}\right)$ was pinned at a smaller value in the tri-anode, compared with the planar Schottky structure. As $V_{\mathrm{SCH}}$ was fixed and did not increase with the reverse bias, the $I_{\mathrm{R}}$ was 


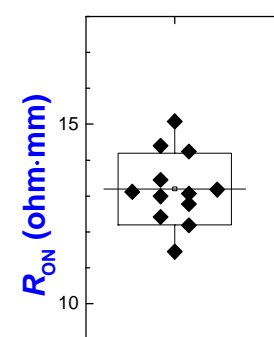

(a)

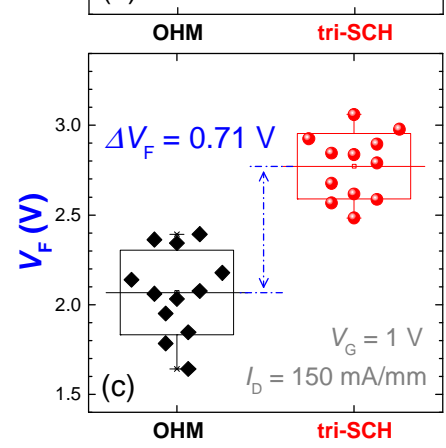

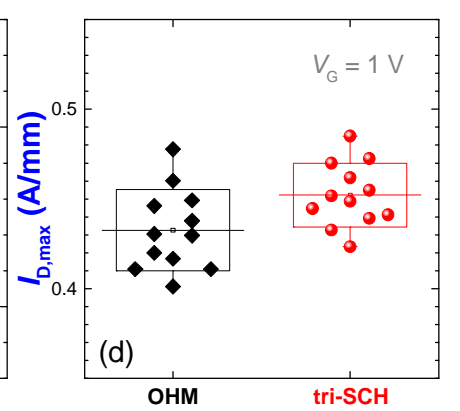

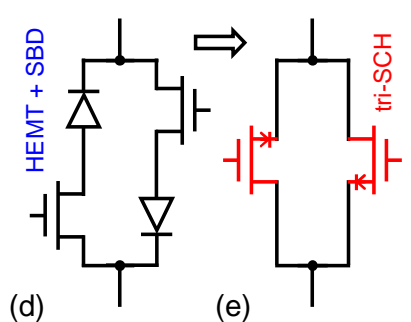

(e)
Fig. 4. Comparison of the tri-SCH and OHM in (a) $R_{\mathrm{ON}}$, (b) maximum $I_{\mathrm{D}}$ $\left(I_{\mathrm{D}, \max }\right)$ and $(\mathrm{c})$ forward voltage $\left(V_{\mathrm{F}}\right)$. Examples of bi-directional power switches using a conventional scheme including two HEMTs and two SBDs (d) and a more advanced scheme using only two reverse-blocking transistors as demonstrated in this work (tri-SCH) (e).

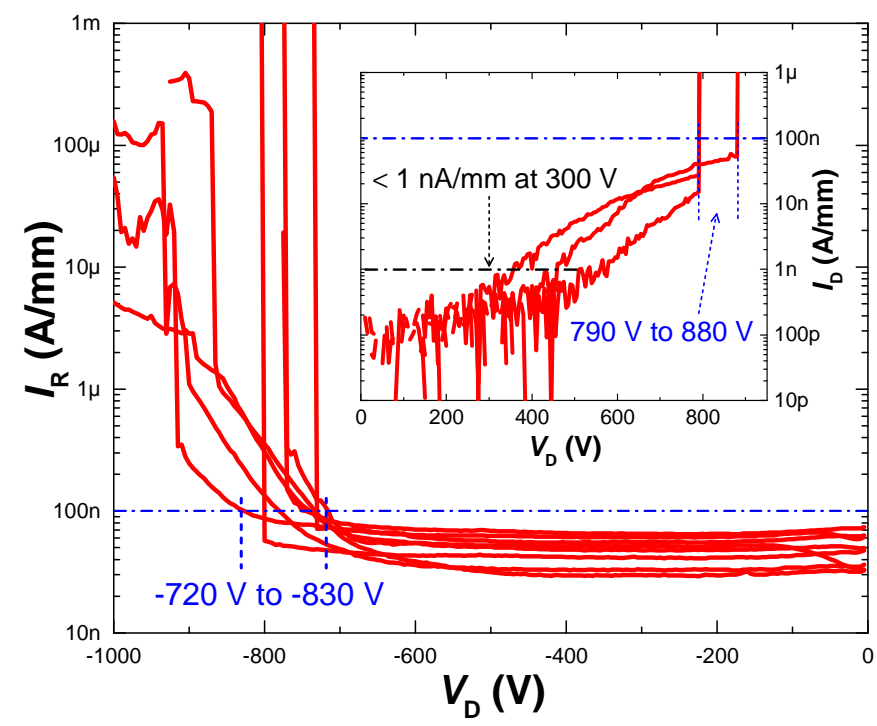

Fig. 5. Room-temperature breakdown characteristics of the tri-SCH, measured with grounded substrate. The $V_{\mathrm{G}}$ for measuring the $V_{\mathrm{RB}}$ and $V_{\mathrm{B}}$ was $0 \mathrm{~V}$ and -10 $\mathrm{V}$, respectively.

constant even at high reverse biases (Fig. 3(b)), and was not affected by the $V_{\mathrm{G}}$ for a large range of voltages from $-10 \mathrm{~V}$ to $6 \mathrm{~V}$ (Fig. 3(c)). Another improvement with the tri-anode Schottky drain was the better uniformity of the $I_{\mathrm{R}}$. The variation of the $I_{\mathrm{R}}$ is about three orders of magnitude for the p$\mathrm{SCH}$, while less than $50 \mathrm{nA} / \mathrm{mm}$ for the tri-SCH. As shown in Fig. 3(d), the $I_{\mathrm{R}}$ of the tri-SCH was small and below $1 \mu \mathrm{A} / \mathrm{mm}$ at even $150{ }^{\circ} \mathrm{C}$, revealing the potential of this structure for high-temperature applications.

In addition to its excellent reverse blocking capability, the tri-anode Schottky drain did not degrade the ON-state characteristics of the transistors. The $R_{\mathrm{ON}}$ and $I_{\mathrm{D}}$ of the tri-
Table 1. Comparison of the tri-SCH with reverse-blocking GaN (MOS)HEMTs in the literature.

\begin{tabular}{|c|c|c|c|c|c|}
\hline & Substrate & $V_{\mathbf{R B}}$ & $\begin{array}{c}I_{\mathrm{R}} \\
(\mu \mathrm{A} / \mathbf{m m})\end{array}$ & $\begin{array}{l}V_{\text {ON }} \\
(\mathrm{V})\end{array}$ & $\begin{array}{l}\Delta V_{\mathbf{F}} \\
(\mathbf{V})\end{array}$ \\
\hline $\begin{array}{l}\text { This } \\
\text { work }\end{array}$ & $\mathrm{Si}$ & $\begin{array}{l}-759 \pm 37 \mathrm{~V} \\
\text { at } 0.1 \mu \mathrm{A} / \mathrm{mm} \\
\text { (grounded sub.) }\end{array}$ & $\begin{array}{l}0.065 \pm 0.011 \\
\text { at }-700 \mathrm{~V} \\
\text { (grounded sub.) }\end{array}$ & $\begin{array}{c}0.64 \pm \\
0.02\end{array}$ & 0.7 \\
\hline [1] & $\mathrm{Si}$ & $\begin{array}{l}-321 \mathrm{~V} \text { at } 1 \mathrm{~mA} / \mathrm{mm} \\
\text { (floating sub.) } \\
-200 \mathrm{~V} \text { at } 1 \mathrm{~mA} / \mathrm{mm} \\
\text { (grounded sub.) }\end{array}$ & $\begin{array}{l}\geq 10 \text { at }-75 \mathrm{~V} \\
\text { (floating sub.) }\end{array}$ & 0.55 & 1.25 \\
\hline$[2]$ & $\mathrm{SiC}$ & $-110 \mathrm{~V}$ at $10 \mathrm{~mA} / \mathrm{mm}$ & $\geq 1000$ at $-20 \mathrm{~V}$ & -- & -- \\
\hline [3] & $\mathrm{Si}$ & $\begin{array}{l}-685 \mathrm{~V} \text { at hard } \\
\text { breakdown }^{\mathrm{a}}\end{array}$ & $\sim 6$ at $-100 \mathrm{~V}^{\mathrm{a}}$ & 0.4 & -- \\
\hline$[4]$ & $\mathrm{Al}_{2} \mathrm{O}_{3}$ & $-49 \mathrm{~V}$ at $1 \mathrm{~mA} / \mathrm{mm}$ & $>100$ at $-25 \mathrm{~V}$ & 1.7 & $\geq 2$ \\
\hline$[5]$ & $\mathrm{Si}$ & -- & $\begin{array}{l}\sim 0.4 \text { at }-20 \mathrm{~V} \\
\text { (floating sub.) }\end{array}$ & 1.91 & -- \\
\hline [7] & $\mathrm{Si}$ & $\begin{array}{l}-650 \mathrm{~V} \text { at } \sim 0.15 \\
\mathrm{~mA} / \mathrm{mm}^{\text {a }}\end{array}$ & -- & 1.5 & -- \\
\hline [6] & $\mathrm{Si}$ & $-900 \mathrm{~V}$ at $1 \mu \mathrm{A} / \mathrm{mm}^{\mathrm{b}}$ & $\begin{array}{l}\sim 0.25 \mu \mathrm{A} / \mathrm{mm} \\
\text { at }-700 \mathrm{~V}^{\mathrm{b}}\end{array}$ & 0.38 & -- \\
\hline
\end{tabular}

a. Substrate connection not reported

b. Simulation results

SCH were about the same as those of the OHM (Fig. 4(a) and (b)). The forward voltage $\left(V_{\mathrm{F}}\right)$ for the tri-SCH and the $\mathrm{OHM}$ was $2.77 \pm 0.17 \mathrm{~V}$ and $2.07 \pm 0.17 \mathrm{~V}$, respectively, extracted at $I_{\mathrm{D}}=150 \mathrm{~mA} / \mathrm{mm}$, rendering a small $\Delta V_{\mathrm{F}}$ of $0.7 \mathrm{~V}$ (Fig. $\left.4(\mathrm{c})\right)$ which was very close to the $V_{\mathrm{ON}}$ of the tri-anode SBD. This is very important to improve the efficiency while reducing the size and complexity of power converters. For instance, the number of components in a bi-directional power switch can be reduced from four to two using the tri-SCH (Fig. 4(d) and (e)), and the resistive loss from the SBDs can be eliminated as the $\Delta V_{\mathrm{F}}$ is so close to the $V_{\mathrm{ON}}$ and the $R_{\mathrm{ON}}$ of the tri-SCH is about the same as that of the OHM.

Figure 5 shows the breakdown characteristics of the tri$\mathrm{SCH}$ under both forward and reverse drain voltages. The breakdown voltage in this work was defined at a leakage current of $0.1 \mu \mathrm{A} / \mathrm{mm}$ with the $\mathrm{Si}$ substrate grounded. The reverse breakdown voltage $\left(V_{\mathrm{RB}}\right)$ varied from $-720 \mathrm{~V}$ to $-830 \mathrm{~V}$ under $V_{\mathrm{G}}=0 \mathrm{~V}$, along with a consistently small $I_{\mathrm{R}}$ of $65 \pm 11$ $\mathrm{nA} / \mathrm{mm}$ at $-700 \mathrm{~V}$. The forward breakdown voltage $\left(V_{\mathrm{B}}\right)$ varied from $790 \mathrm{~V}$ to $880 \mathrm{~V}$ (the inset of Fig. 5), which was measured under a $V_{\mathrm{G}}$ of $-10 \mathrm{~V}$.

The tri-SCH was compared with other reverse-blocking $\mathrm{GaN}$ transistors in the literature in Tab. 1. The tri-SCH presented the highest $V_{\mathrm{RB}}$, the lowest $I_{\mathrm{R}}$ and the smallest $\Delta V_{\mathrm{F}}$, despite the grounded substrate and the much stricter definition of $V_{\mathrm{RB}}$ in this work, along with a small $V_{\mathrm{ON}}$ comparable to the state-of-the-art results.

The forward and reverse performance of the tri-SCH were further benchmarked against state-of-the-art discrete lateral GaN-on-Si power (MOS)HEMTs and SBDs in Fig. 6, respectively. For calculation of the figure-of-merit (FOM) in this work, average $R_{\mathrm{ON}}(13.2 \pm 1.1 \Omega \cdot \mathrm{mm}), V_{\mathrm{RB}}(-759 \pm 37 \mathrm{~V}$ at $0.1 \mu \mathrm{A} / \mathrm{mm})$ and $V_{\mathrm{B}}(820 \pm 42 \mathrm{~V}$ at $0.1 \mu \mathrm{A} / \mathrm{mm})$ were adopted, along with a total transfer length of $3 \mu \mathrm{m}$, accounting for both source and drain contacts. The tri-SCH presented high

(C) 2018 IEEE. Personal use of this material is permitted. Permission from IEEE must be obtained for all other uses, in any current or future media, including reprinting/republishing this material for advertising or promotional purposes, creating new collective works, for resale or redistribution to servers or lists, or reuse of any copyrighted component of this work in other works. 
(a) Forward
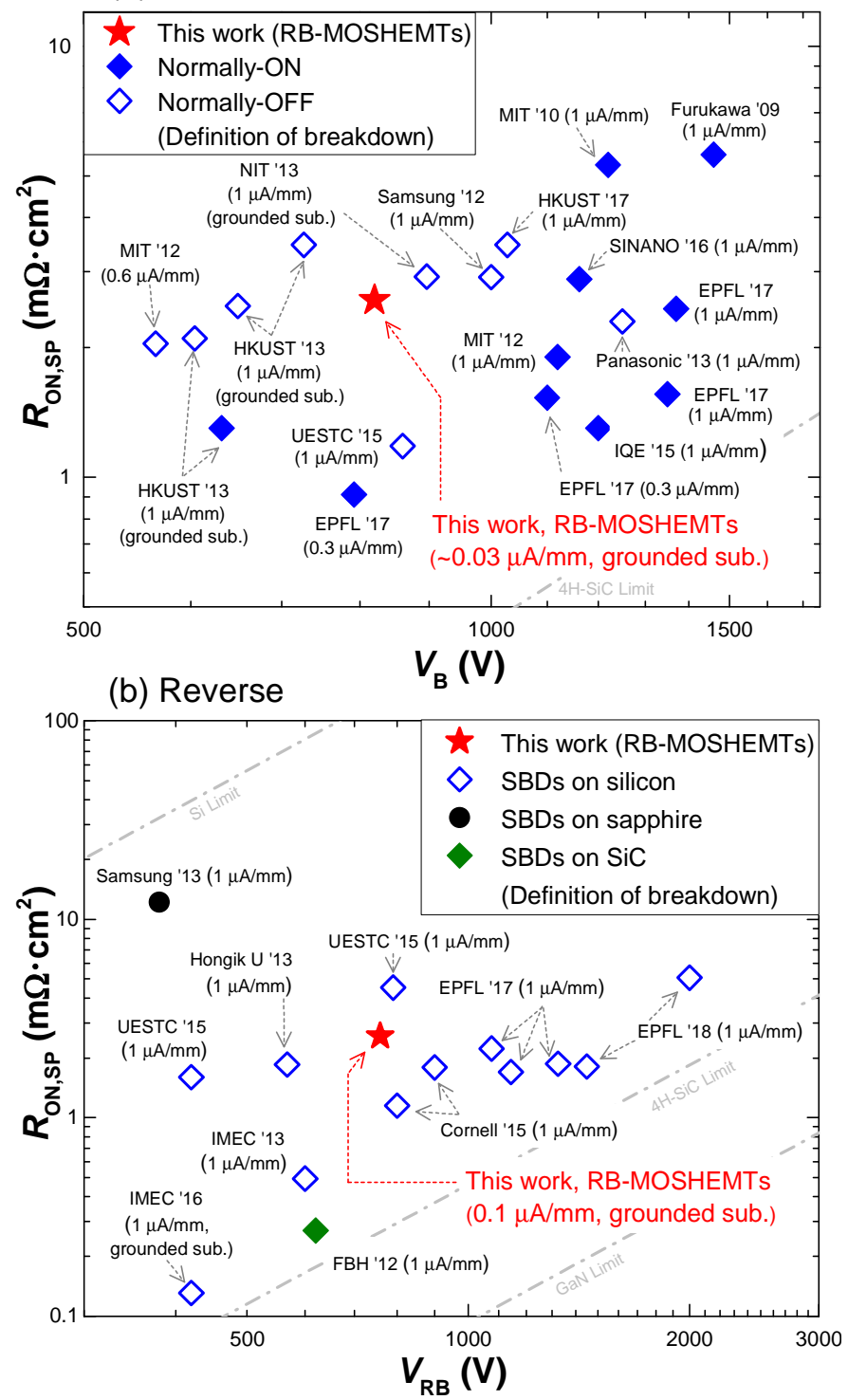

Fig. 6. $R_{\mathrm{ON}, \mathrm{SP}}$ versus breakdown voltage benchmarks of (a) the forward performance of the tri-SCH (RB-MOSHEMTs) against discrete lateral GaNon-silicon power (MOS)HEMTs and (b) their reverse performance against discrete lateral GaN SBDs on various substrates. The breakdown voltage for all reference devices was re-calculated based on the reported data following the definition of $V_{\mathrm{B}}$ at $I_{\mathrm{OFF}} \leq 1 \mu \mathrm{A} / \mathrm{mm}$. For fair comparison, literature results with unspecified $R_{\mathrm{ON}}$ or $I_{\mathrm{R}}$ were not included.

$V_{\mathrm{B}}$ and $V_{\mathrm{RB}}$, comparable to state-of-the-art discrete devices measured with grounded substrates, but at a much smaller current, revealing its excellent performance as uni-directional power switches. More importantly, these high blocking voltages under both forward and reverse biases were achieved in a single integrated device, instead of using a discrete transistor in series with an SBD, which can greatly simplify the circuit design, reduce its size, resistance and parasitic components, and improve the efficiency of power converters.

\section{CONCLUSION}

In this work we presented high-performance reverseblocking GaN power MOSHEMTs on $\mathrm{Si}$, by integrating tri- anode SBDs and slanted tri-gate FPs as the drain electrode. The device presented high $V_{\mathrm{RB}}$ of $-759 \pm 37 \mathrm{~V}$ at $0.1 \mu \mathrm{A} / \mathrm{mm}$ with grounded substrate, along with small $V_{\mathrm{ON}}$ and zero degradation in $R_{\mathrm{ON}}$ and $I_{\mathrm{D}}$. These results can potentially enable $\mathrm{GaN}$ transistors as uni-directional power switches for power conversion and open enormous opportunities for highly integrated $\mathrm{GaN}$ power devices for future advanced power applications.

\section{REFERENCES}

[1] C. Zhou, W. Chen, E. L. Piner and K. J. Chen, "Schottky-ohmic drain AlGaN/GaN normally off HEMT with reverse drain blocking capability," IEEE Electron Device Lett., vol. 31, no. 7, pp. 668-670, Jul. 2010.

[2] E. Bahat-Treidel, R. Lossy, J. Wurfl and G. Trankle, "AlGaN/GaN HEMT with integrated recessed Schottky-drain protection diode," IEEE Electron Device Lett., vol. 30, no. 9, pp. 901-903, Sept. 2009.

[3] J. -G. Lee, S. -W. Han, B. -R. Park, and H. -Y. Cha, "Unidirectional AlGaN/GaN-on-Si HFETs with reverse blocking drain," Appl. Phys. Express, vol. 7, pp. 014101-1-014101-4, Dec. 2013.

[4] S. -L. Zhao, M. -H. Mi, B. Hou, J. Luo, Y. Wang, Y. Dai, J. -C. Zhang, X. -H. Ma, and H. Yue, "Mechanism of improving forward and reverse blocking voltages in AlGaN/GaN HEMTs by using Schottky drain," Chinese Phys. B, vol. 23, pp. 107303-1-107303-5, Aug. 2014.

[5] A. Taube, J. Kaczmarski, R. Kruszka, J. Grochowski, K. Kosiel, J. Gołaszewska-Malec, M. Sochacki, W. Jung, E. Kamińska, and A. Piotrowska, "Temperature-dependent electrical characterization of highvoltage AlGaN/GaN-on-Si HEMTs with Schottky and ohmic drain contacts," Solid-State Electron., vol. 111, pp. 12-17, Sept. 2015.

[6] Y. Shi, W. Chen, C. Liu, G. Hu, J. Liu, X. Cui, H. Tao, J. Zhang, Y. Shi, A. Zhang, Z. Li, Q. Zhou, and B. Zhang, "A high-performance GaN Emode reverse blocking MISHEMT with MIS field effect drain for bidirectional switch," 2017 29th International Symposium on Power Semiconductor Devices and IC's (ISPSD), Sapporo, 2017, pp. 207-210.

[7] T. Morita, M. Yanagihara, H. Ishida, M. Hikita, K. Kaibara, H. Matsuo, Y. Uemoto, T. Ueda, T. Tanaka, and D. Ueda, "650 V $3.1 \mathrm{~m} \Omega \cdot \mathrm{cm}^{2}$ GaN-based monolithic bidirectional switch using normally-off gate injection transistor," 2007 IEEE International Electron Devices Meeting (IEDM), Washington, DC, 2007, pp. 865-868.

[8] J. Ma and E. Matioli, "High-Voltage and Low-Leakage AlGaN/GaN Tri-Anode Schottky Diodes With Integrated Tri-Gate Transistors," IEEE Electron Device Lett., vol. 38, pp. 83-86, Jan. 2017.

[9] J. Ma, D. C. Zanuz and E. Matioli, "Field Plate Design for Low Leakage Current in Lateral GaN Power Schottky Diodes: Role of the Pinch-off Voltage," IEEE Electron Device Lett., vol. 38, pp. 1298-1301, Sept. 2017.

[10] J. Ma, M. Zhu and E. Matioli, "900 V Reverse-Blocking GaN-on-Si MOSHEMTs With a Hybrid Tri-Anode Schottky Drain," IEEE Electron Device Lett., vol. 38, pp. 1704-1707, Dec. 2017.

[11] J. Ma and E. Matioli, "Slanted Tri-Gates for High-Voltage GaN Power Devices," IEEE Electron Device Lett., vol. 38, pp. 1305-1308, Sept. 2017.

[12] J. Ma and E. Matioli, "2 kV slanted tri-gate GaN-on-Si Schottky barrier diodes with ultra-low leakage current," Appl. Phys. Lett., vol. 112, pp. 052101-1-052101-4, Jan. 2018.

[13] J. Ma and E. Matioli, "High Performance Tri-Gate GaN Power MOSHEMTs on Silicon Substrate," IEEE Electron Device Lett., vol. 38, no. 3, pp. 367-370, Mar. 2017.

[14] E. Matioli, B. Lu and T. Palacios, "Ultralow Leakage Current AlGaN/GaN Schottky Diodes With 3-D Anode Structure," IEEE Trans. Electron Devices, vol. 60, no. 10, pp. 3365-3370, Oct. 2013.

[15] J. Ma, G. Santoruvo, P. Tandon and E. Matioli, "Enhanced Electrical Performance and Heat Dissipation in AlGaN/GaN Schottky Barrier Diodes Using Hybrid Tri-anode Structure," IEEE Trans. Electron Devices, vol. 63, no. 9, pp. 3614-3619, Sept. 2016. 